\title{
The evolution of medical care: from the beginnings to personalized medicine
}

\author{
Dimitris Koutsouris ${ }^{1}$
}

Received: 1 December 2016 / Accepted: 6 December 2016/Published online: 13 December 2016

(C) IUPESM and Springer-Verlag Berlin Heidelberg 2016

The practice of medical care is as old as the first recordings in human history, conceiving the human body and disease in a holistic manner. Early medical traditions include those of ancient Egypt and Babylon. The Greeks went even further, introducing the concepts of medical diagnosis, prognosis, and advanced medical ethics. Around 800 BCE Homer in The Iliad gives descriptions of wound treatment by the two sons of Asklepios, the admirable physicians Podaleirius and Machaon and one acting doctor, Patroclus. The Hippocratic Oath, still taken by doctors up to today, was written in Greece in the fifth century BCE. In the medieval age, surgical practices inherited from the ancient masters were improved and then systematized in Rogerius's The Practice of Surgery. Universities began systematic training of physicians around the years 1220 in Italy. During the Renaissance, understanding of anatomy improved with pioneering works such as those from Andreas Vesalius, and the microscope was invented. The germ theory of disease in the nineteenth century led to cures for many infectious diseases. Military doctors advanced the methods of trauma treatment and surgery. Public health measures were developed especially in the nineteenth century as the rapid growth of cities required systematic sanitary measures. Advanced research centers opened in the early twentieth

This article is part of the Topical collection on Systems Medicine

Dimitris Koutsouris

dkoutsou@biomed.ntua.gr

1 National Technical University of Athens, Athens, Greece century, often connected with major hospitals. The midtwentieth century was characterized by new biological treatments, such as antibiotics. These advancements, along with developments in chemistry, genetics, and lab technology (such as the x-ray) led to modern medicine. Medicine was heavily professionalized in the twentieth century, and new careers opened to women as nurses (from the 1870s) and as physicians (especially after 1970) and at the same time disease specialization arose in the sense of providing medical care with respect to the specific characteristics of the disease as well as provided from specialized medical professionals. The twenty-first century is characterized by highly advanced research involving numerous fields of science.

Yet, the advancement of medical care was moving hand in hand with technological advancement. Besides basic knowledge of biomedical processes, technology was the main implementer of that knowledge. The twenty-first century could be characterized by the phrase "Biology is the new Physics", stated in an article by Philip Hunter in 2010. ${ }^{1}$ These very technological breakthroughs, which include the innovations in semi-conductors, the increase in computational power along with the lowering of cost of computational power, were the main factors for the onset of personalized medicine. It would be unthinkable to speak of such applications such as providing health care based on the patients profile without the use of high throughput screening methods, such as microarrays and next generation sequencing (NGS). Or it would be impossible to interpret genomic data without the analytical and mathematical tools from physics, mathematics and engineering. Hence, it was the "marriage" of biology and engineering that brought

\footnotetext{
${ }^{1}$ EMBO Rep. 2010 May; 11(5): 350-352.
} 
about such possibilities. Further on, pioneering work in engineering has created new possibilities through the application of biosensors, nanoparticles and nano-bots, advanced imaging methodologies, as well as improved procedures towards the understanding of biological signal transduction and information transmission. This interdisciplinary interaction gave the possibility of predicting the health risks of an individual based on his/hers genomic profile (still considering that this process is in its infancy and there are more to be learned about). At the same time, those new analytical tools gave the possibility of treating human disease from a holistic perspective, yet this time considering biological systems as a complete entity and not as isolated molecular events.
Hence, there should be an increasing effort towards the intercoupling of the biological sciences with engineering, since this is, a one-way road to the improvement of medical care and consequently to personalized medicine.

Compliance with ethical standards

Conflict of interest No conflict of interest.

Funding There is no funding source.

Ethical approval This article does not contain any studies with human participants or animals performed by any of the authors.

Informed consent Not applicable. 